\title{
ASSESSMENT AND MAPPING OF RAINFALL EROSIVITY INDEX (R) FOR MAJHA REGION, PUNJAB IS A STATE IN NORTHERN, INDIA Prashant Kumar
}

Department of Agricultural Engineering, Khalsa College, Amritsar, Punjab. Email: er.prashant2929@gmail.com

Article History: Received on $23^{\text {rd }}$ March 2021, Revised on $30^{\text {th }}$ July 2021, Published on $4^{\text {th }}$ August 2021

\begin{abstract}
Purpose: This study gives a critical assessment of the rainfall erosivity factor $(\mathrm{R})$ for selected sites in the Majha region, representing different locations use of mean monthly rainfall data.

Methodology: By applying empirical methods, the rainfall intensity for all the locations were obtained and was further determined at three different intervals of 30-minutes, 45-minutes and 60-minutes, respectively. The rainfall erosivity factor $(\mathrm{R})$ was calculated by the revised universal soil loss equation (RUSLE).

Main Findings: Using RUSLE, the rainfall erosivity factor $(\mathrm{R})$ for each of the locations was measured as follows; EI = 3878.49 (MJmmha-1hr-1), EI = 4013.71 (MJmmha-1hr-1), EI = 4302.24 (MJmmha-1hr-1) for Majha region of Amritsar, Tarntaran and Pathankot respectively. A close observation of the data obtained revealed that as rainfall intensity increased with the duration, the rainfall erosivity index reduced or decreased.

Implications of study: Nevertheless, it is expected that if proper cover crop and management practices are applied despite the region, the study area falls within, rainfall erosivity can be cushioned, thus reducing further erosion tendencies and enhancing food production chances from productive lands within the area.
\end{abstract}

The novelty of study: The rainfall erosivity factor $(\mathrm{R})$ was calculated by the revised universal soil loss equation (RUSLE).

\section{Keywords: Soil Erosion, Rainfall, Erosivity Index, Rainfall Intensity, RUSLE, Punjab. \\ INTRODUCTION}

Rainfall is a key contributing factor to land degradation, such as soil erosion. This is a result of the ability of rainfall to dissolve, loosen or worn away soil by the force of raindrops, runoffs, and river flooding and deposit in other places (Balogun et al. 2012; World Meteorological Organization 2005). Rainfall erosivity concerns the ability of rainfall to precipitate soil loss Nearing, M.A.; Yin, S.; Borrelli, P.; Polyakov, V.O. (2017) as it supplies energy to the mechanical processes of soil erosion. Agricultural soils are the richest materials of minerals, nutrients, moisture, air, organic substances and microbial sports that guide plant increase and manufacturing. They provide the pathways via which water and vitamins move to the roots of plants, and they are the matrix of nutrient transformation with the resultant surroundings for micro-organisms and fauna Powlson et al., (2011). Suresh (2012) stated equally that erosion occurs in three phenomena detachment, transportation and deposition, and rainfall creates the medium through which all of them take area. Rainfall is one of the main causes of soil erosion because it separates and displaces soil particles. Raindrop distribution, duration, and terminal velocity in relation to soil detachment and displacement are difficult to measure precisely Talchabhadel, R., Nakagawa, H., Kawaike, K. et al. (, 2020). The capacity of rainfall to motive soil disturbance, detachment, transport and eventual deposition, which ends up in soil erosion, is thought of as rainfall erosivity (R). According to Michael and Ojha (2003), the power for erosion depends on certain factors, which encompass soil nature/traits, slope/topography, presence of vegetative cowl and classy climatic situations. The important contributing element to soil loss and movement is rainfall and its characteristics (depth, duration, frequency, energy, distribution etc.) Okorafor et al., (2017). Rainfall is the primary water-driven force that causes soil erosion, and rainfall erosivity, which is proportional to raindrop kinetic energy, reflects its potential impact on soil erosion (Dai, Q., Zhu, J., Zhang, S., Zhu, S., Han, D., and Lv, G. (2020). The erosive ability of rainfall to initiate soil detachment, movement/transportation and eventual deposition in one-of-a-kind places is regarded because of the erosivity of rainfall. Rainfall erosivity aspect $(\mathrm{R})$ is one of the six factors of the commonplace Universal Soil Loss Equation (Wischmeier and Smith, 1978) and revised customary Soil Loss Equation (Renard et al., 1997) that is stated hence;

$A=R \times \mathrm{K} \times \mathrm{L} \times S \times C \times \mathrm{P}$

Where A= Annual soil Loss, $\mathrm{R}=$ Rainfall Erosivity Factor, $\mathrm{K}=$ Soil Erodibility Factor $\mathrm{S}=$ Slope Length factor, $\mathrm{S}=$ Steepness Factor, $\mathrm{C}=$ Cover Crop Management Factor P= Conservation/Management Practices Factor.

Rainfall erosivity issue is reckoning on the amount, length, intensity, driblet length, distribution, frequency and kinetic strength of a rainfall/storm event (Okorafor et al., 2017). downfall erosivity is of dominant significance amongst natural factors poignant erosion, and in contrast to other natural parts, together with relief or soil traits, isn't amenable to human change (Angelo-Martinez and Beguaria, 2009). The target of this study is to create the use of mean monthly rainfall data 
to an assessment and mapping of rainfall erosivity index/factor $(\mathrm{R})$ for the Majha region; Punjab is a state in northern India.

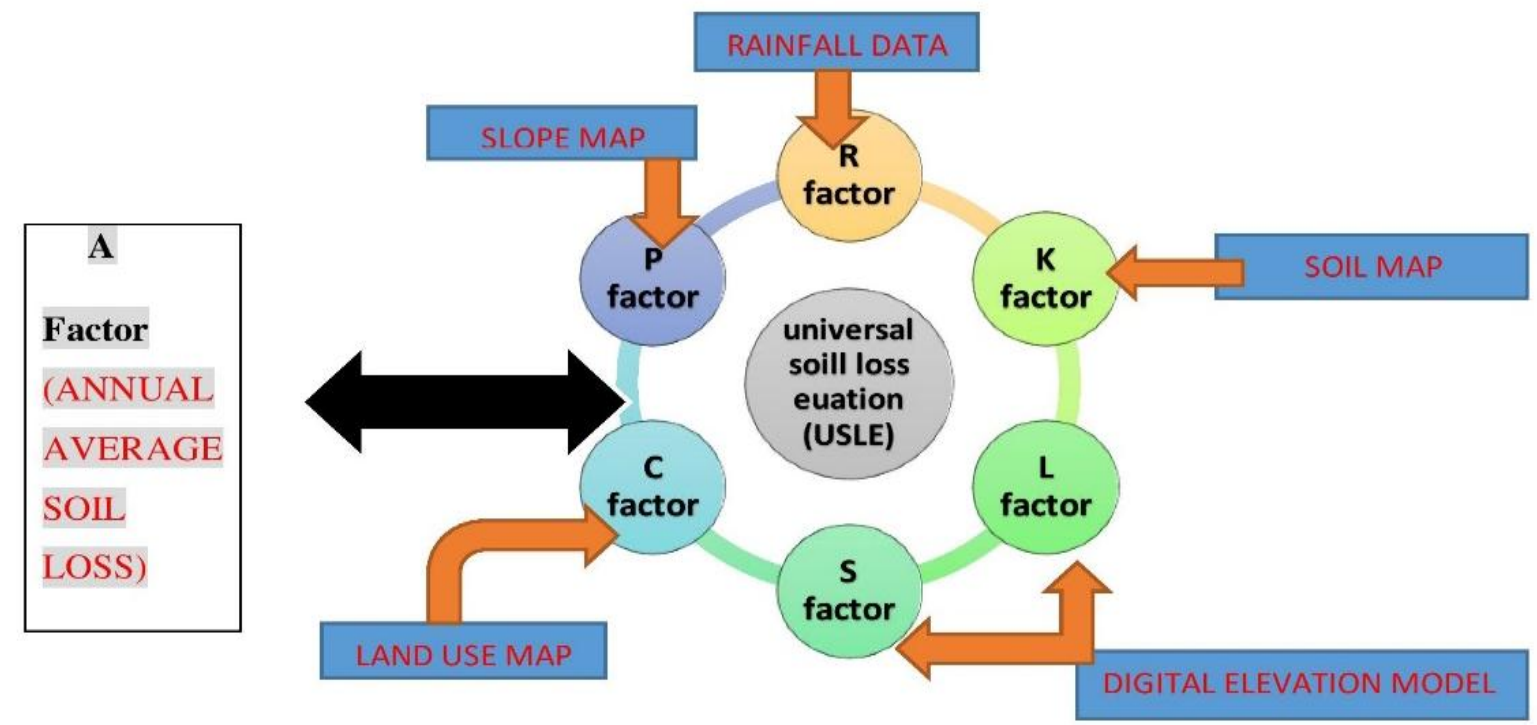

Figure 1: Methodological flow chart for the preparation of soil loss assessment USLE

\section{MATERIALS AND METHODS}

\section{Description of Study Area}

The presented study area is the Majha is a region of the state of Punjab; India Majha is a region located in the central parts of the historical Punjab region split between India and Pakistan. It extends north from the right bank of the river Beas and reaches as far north as the river Jhelum. The Majha region of Indian State of Punjab covers the area between Beas and Ravi rivers, including the area on the north of Sutlej, after the confluence of Beas and Sutlej in tarn taran district, extending up to the Ravi River, which is all part of the Majha region in India. This region contains districts of the Indian state of Punjab Amritsar, Tarn Taran, and Pathankot. The study area is the Majha region of the district located within respectively Latitudes $31.6340^{\circ} \mathrm{N}$ and longitude $74.8723^{\circ} \mathrm{E}$, latitude $32.2733^{\circ} \mathrm{N}$ and longitude $75.6522^{\circ} \mathrm{E}$ and latitude $31.4539^{\circ} \mathrm{N}$, longitude $74.9268^{\circ} \mathrm{E}$ and an average elevation of respectively 234 meters, 226 meters and 332 meters. The annual average rainfall is concerning, respectively $703.4(\mathrm{~mm}), 812(\mathrm{~mm})$ and $1335(\mathrm{~mm})$. Wheat and paddy are that the major crop of the Majha region Sugarcane, maize, pulses, oilseed crops, vegetables and fruits are full-grown within the region.

\section{DATA AND COLLECTION AND COMPUTATION}

In order to determine the rainfall erosivity factor $(\mathrm{R})$ of the selected locations, rainfall data (Mean monthly rainfall amount and rainfall days) were obtained from Sri Guru Ram Dass Jee International Airport (regional Meteorological research Centre) Amritsar, Majha region, Punjab for a period of 30 years (1981-2010).

\section{Determination of erosivity index}

Rainfall erosivity ( $\mathrm{R}$ factor) describes the soil loss potential caused by rainfall, and it is calculated as total kinetic energy (E) of the storm times its 30 minutes intensity (I30). Erosivity index is not simply an energy parameter, and it is not just a good indicator of erosive potential (Erasmus et al., 1970; Satapathy, 2000) but also indicates the volume of rainfall and runoff; however, rain of lower intensity occurring for a longer duration may have the same energy value as a short duration rain of much higher intensity. The I30 components specify the prolonged peak rates of detachment and runoff. Thus, the term erosivity index is a statistical interaction that shows how total energy and peak intensity are combined in each particular storm. Technically, it indicates how the detachment of soil particles is being combined with its transporting capacity (ARS, 1961; Jaiswal, 1982). According to Sanchez-Moreno et al. (2013); Oliveira et al. (2012), rainfall erosivity factor $(\mathrm{R})$ is computed thus;

$R=\Sigma(E I 30)$

Where $\mathrm{R}=$ Rainfall Erosivity Factor

$\mathrm{I} 30=30$ minutes rainfall intensity

$\mathrm{E}=$ Total Storm Kinetic Energy

The kinetic energy of the storm or rainfall event is obtained from the following relationship according to Teh (2011); 
Where $\mathrm{E}=$ total kinetic energy

\section{$\mathrm{I}=$ Rainfall Intensity}

The rainfall intensity (I), which is the rate of rainfall express as depth per time (Michael and Ojha, 2003), is given by $\underline{\text { Yin }}$ et al. (2007) as;

$I=P T /$

Where $\mathrm{P}=$ Precipitation

$\mathrm{T}=$ Duration of Rainfall

The resultant 30-minute interval rainfall (I30) is also obtained according to Yin et al. (2007) as;

$I_{30}=P_{30} / 0.5 h$

Where, $\quad P_{30}=$ Maximum 30 minute rainfall

$0.5 \mathrm{~h}=30$ minutes duration

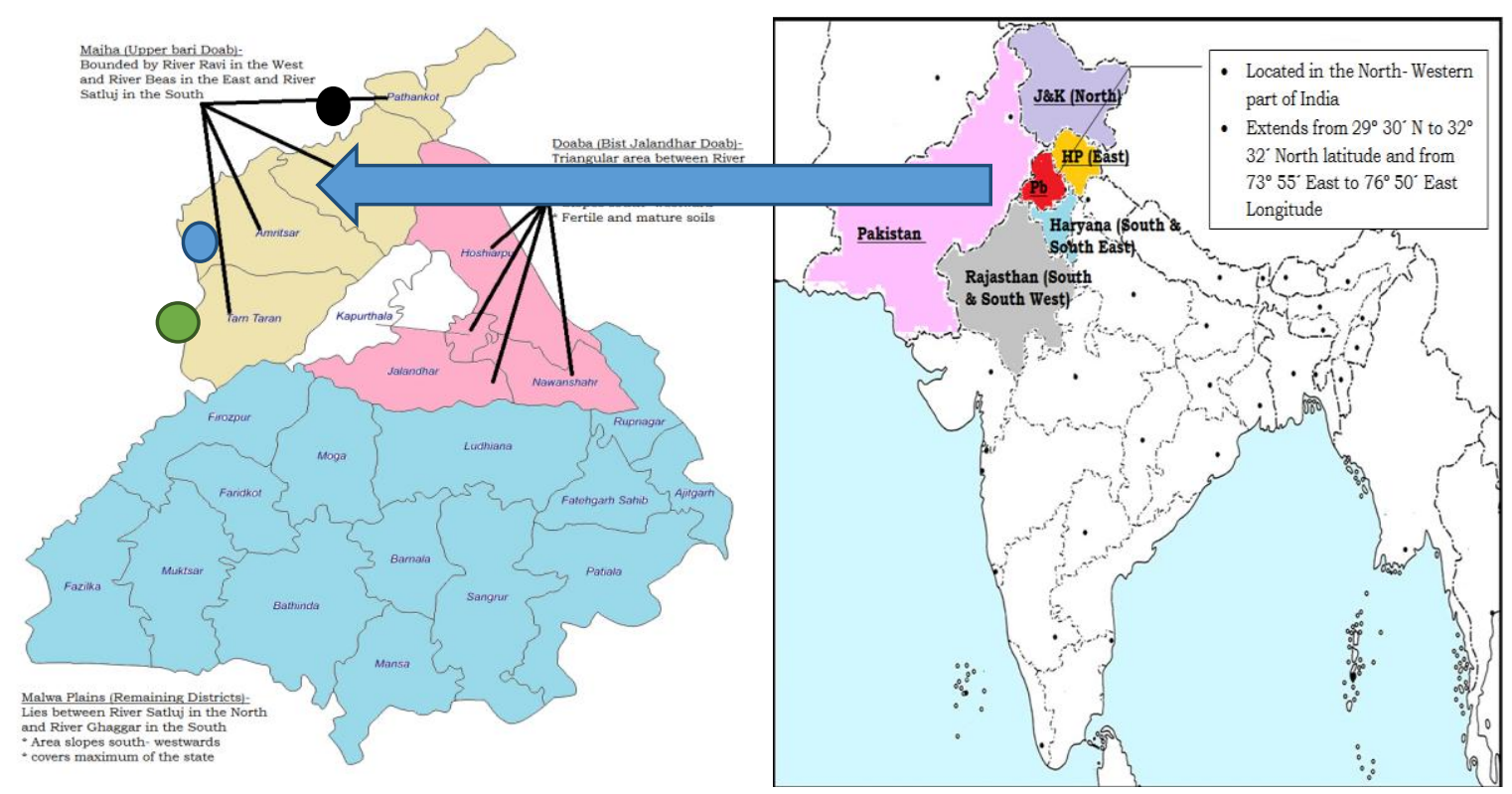

Figure 2: Location of the study area Majha region

\section{RESULTS}

From Tables 1-3. The rainfall data obtained for the specified period of the 30 years (1981-2010) were grouped according to mean rainfall amount and mean rainfall days. Figure 2-4 Show all locations within the mean rainfall amount (MRA) and mean rainfall day (MRD). The data were then subjected to statistical analysis and, therefore, the mean (X), variance (SD) and coefficient of variation where respectively district Amritsar is 58.61, 64.63 and 1.10, Tarn Taran is 67.67, 62.91 and 0.9297, and Pathankot is 111.25, 122.25, and 1.098. Based on the thirty-year rainfall data used rainfall intensity for different time intervals I30 minutes, I45 minutes and I60 minutes was obtained and based on the varying time intervals, the kinetic energy and rainfall erosivity factor $(\mathrm{R})$ were also obtained for all the various locations representing Majha region as well. The results for rainfall intensity, kinetic energy and rainfall erosivity factor (R) for each location are as shown in Tables 4-6.

The summary of the mean rainfall erosivity factor (R), i.e. EI30 for all the locations Majha region, is also shown in Table 7. Table 8 contains classification information on the corresponding rainfall erosivity range values for various rainfall erosivity classes, and from the range of values obtained for each of the locations, it was observed that all the locations within the Majha region fall within the erosivity range values class of medium erosivity on a range of 3878.49 (MJmmha-1hr-1), 4013.71 (MJmmha-1hr-1), 4302.24 (MJmmha-1hr-1).

Table 1: Mean Rainfall Amount and Rainfall Days for the location Amritsar (1981- 2010)

\begin{tabular}{llllll}
\hline MONTH & M.R.A $(\mathbf{c m})$ & M.R.D (days) & $\left(\boldsymbol{X}_{\mathbf{1}}-\mathbf{X}\right)$ & $\left(\boldsymbol{X}_{\mathbf{1}}-\mathbf{X}\right)$ & Mean monthly hour \\
\hline JAN & 26.2 & 2.1 & -32.4167 & 1050.842439 & 181.7 \\
\hline FEB & 38.6 & 3.3 & -20.0167 & 400.6682789 & 192.7 \\
\hline MAR & 38.4 & 3.2 & -20.2167 & 408.7149589 & 219.4 \\
\hline
\end{tabular}


https://doi.org/10.18510/ijsrtm.2021.932

\begin{tabular}{llllll}
\hline APR & 21.4 & 2.0 & -37.2167 & 1385.082759 & 265 \\
\hline MAY & 26.7 & 2.4 & -31.9167 & 1018.675739 & 294.7 \\
\hline JUNE & 61.2 & 3.8 & 2.5833 & 6.67343889 & 269 \\
\hline JULY & 210.1 & 8.9 & 151.4833 & 22947.19018 & 215.7 \\
\hline AUG & 167.3 & 6.9 & 108.6833 & 11812.0597 & 227.7 \\
\hline SEP & 77.5 & 3.5 & 18.8833 & 356.5790189 & 240.8 \\
\hline OCT & 16.1 & 1.1 & -42.5167 & 1807.669779 & 253.2 \\
\hline NOV & 6.3 & 0.6 & -52.3167 & 2737.037099 & 220.1 \\
\hline DEC & 13.6 & 1.4 & -45.0167 & 2026.503279 & 182.2 \\
\hline & $\sum=703.4$ & & & $\sum=45957.69667$ & $\sum=2762$ \\
\hline
\end{tabular}

Where; M.R.A = Mean Rainfall Amount (cm), M.R.D = Mean Rainfall Days (days)

Table 2: Mean Rainfall Amount and Rainfall Days for the location Tarn Taran (1981- 2010)

\begin{tabular}{lllll}
\hline MONTH & MRA $(\mathbf{c m})$ & MRD (days) & $\mathbf{( X 1 - X )}$ & $\mathbf{( X 1 - X ) 2}$ \\
\hline JAN & 41 & 5 & -26.6667 & 711.1111 \\
\hline FEB & 68 & 7 & 0.333333 & 0.111111 \\
\hline MAR & 56 & 8 & -11.6667 & 136.1111 \\
\hline APR & 31 & 5 & -36.6667 & 1344.444 \\
\hline MAY & 23 & 3 & -44.6667 & 1995.111 \\
\hline JUNE & 85 & 4 & 17.33333 & 300.4444 \\
\hline JULY & 203 & 12 & 135.3333 & 18315.11 \\
\hline AUG & 180 & 13 & 112.3333 & 12618.78 \\
\hline SEP & 77 & 8 & 9.333333 & 87.11111 \\
\hline OCT & 15 & 2 & -52.6667 & 2773.778 \\
\hline NOV & 13 & 1 & -54.6667 & 2988.444 \\
\hline DEC & 20 & 3 & -47.6667 & 2272.111 \\
\hline
\end{tabular}

M.R.D = Mean Rainfall Days (days)

Table 3: Mean Rainfall Amount and Rainfall Days for the location Pathankot (1981- 2010)

\begin{tabular}{|c|c|c|c|c|}
\hline MONTH & MRA & MRD & (X1-X) & $(\mathbf{X} 1-\mathrm{X}) \mathbf{2}$ \\
\hline JAN & 71 & 5 & -40.25 & 1620.063 \\
\hline FEB & 80 & 7 & -31.25 & 976.5625 \\
\hline MAR & 81 & 8 & -30.25 & 915.0625 \\
\hline APR & 46 & 5 & -65.25 & 4257.563 \\
\hline MAY & 34 & 3 & -77.25 & 5967.563 \\
\hline JUNE & 78 & 4 & -33.25 & 1105.563 \\
\hline JULY & 356 & 12 & 244.75 & 59902.56 \\
\hline AUG & 370 & 13 & 258.75 & 66951.56 \\
\hline SEP & 140 & 8 & 28.75 & 826.5625 \\
\hline OCT & 25 & 2 & -86.25 & 7439.063 \\
\hline $\mathrm{NOV}$ & 16 & 1 & -95.25 & 9072.563 \\
\hline \multirow[t]{2}{*}{ DEC } & 38 & 3 & -73.25 & 5365.563 \\
\hline & $\sum=1335$ & $\sum=71$ & & $\sum=164400.3$ \\
\hline
\end{tabular}

Where; M.R.A = Mean Rainfall Amount (cm), M.R.D = Mean Rainfall Days (days).

Table 4: Rainfall Intensity (I), Rainfall Energy (E) and Rainfall Erosivity Factor (R) for Amritsar

\begin{tabular}{|c|c|c|c|c|c|c|c|}
\hline $\begin{array}{l}\text { MONT } \\
\text { H }\end{array}$ & $\begin{array}{l}\text { I30 } \\
(\mathbf{c m} / \mathbf{h r} .)\end{array}$ & $\begin{array}{l}\text { I45 } \\
(\mathrm{cm} / \mathrm{hr} .)\end{array}$ & $\begin{array}{l}\text { I60 } \\
(\mathrm{cm} / \mathrm{hr} .)\end{array}$ & $\begin{array}{l}\mathbf{E} \\
\text { (Mjmmha- } \\
\text { 1) }\end{array}$ & $\begin{array}{l}\text { EI30 } \\
\text { (Mjmmha- } \\
\text { 1hr-1) }\end{array}$ & $\begin{array}{l}\text { EI45 } \\
\text { (Mjmmha- } \\
\text { 1hr-1) }\end{array}$ & $\begin{array}{l}\text { EI60 } \\
\text { (Mjmmha- } \\
\text { 1hr-1) }\end{array}$ \\
\hline JAN & 1.13 & 0.99 & 0.81 & 214.9178 & 242.8571 & 212.7686 & 174.0834 \\
\hline FEB & 1.17 & 1.02 & 0.83 & 216.2322 & 252.9916 & 220.5568 & 179.4727 \\
\hline MAR & 1.18 & 1.04 & 0.89 & 216.5537 & 255.5334 & 225.2159 & 192.7328 \\
\hline APR & 1.21 & 1.08 & 0.92 & 217.5023 & 263.1778 & 234.9025 & 200.1021 \\
\hline MAY & 1.22 & 1.06 & 0.93 & 217.8133 & 265.7322 & 230.8821 & 202.5664 \\
\hline JUNE & 1.79 & 1.19 & 1.09 & 232.2982 & 415.8138 & 276.4349 & 253.2051 \\
\hline JULY & 2.49 & 1.79 & 0.98 & 244.7693 & 609.4757 & 438.1371 & 239.874 \\
\hline AUG & 2.27 & 1.49 & 0.96 & 241.2742 & 547.6925 & 359.4986 & 231.6233 \\
\hline SEP & 1.33 & 1.19 & 0.97 & 221.0751 & 294.0299 & 263.0794 & 214.4428 \\
\hline
\end{tabular}




\begin{tabular}{llllllll}
\hline OCT & 1.12 & 1.05 & 0.87 & 214.582 & 240.3318 & 225.3111 & 186.6863 \\
\hline NOV & 1.19 & 1.01 & 0.84 & 216.8726 & 258.0784 & 219.0413 & 182.173 \\
\hline DEC & 1.09 & 0.99 & 0.82 & 213.5561 & 232.7762 & 211.4205 & 175.116 \\
\hline & & & & & $\mathbf{\Sigma = 3 8 7 8 . 4 9}$ & $\mathbf{\Sigma = 3 1 1 7 . 2 4}$ & $\mathbf{\Sigma = 2 4 3 2 . 0 7 7}$ \\
\hline
\end{tabular}

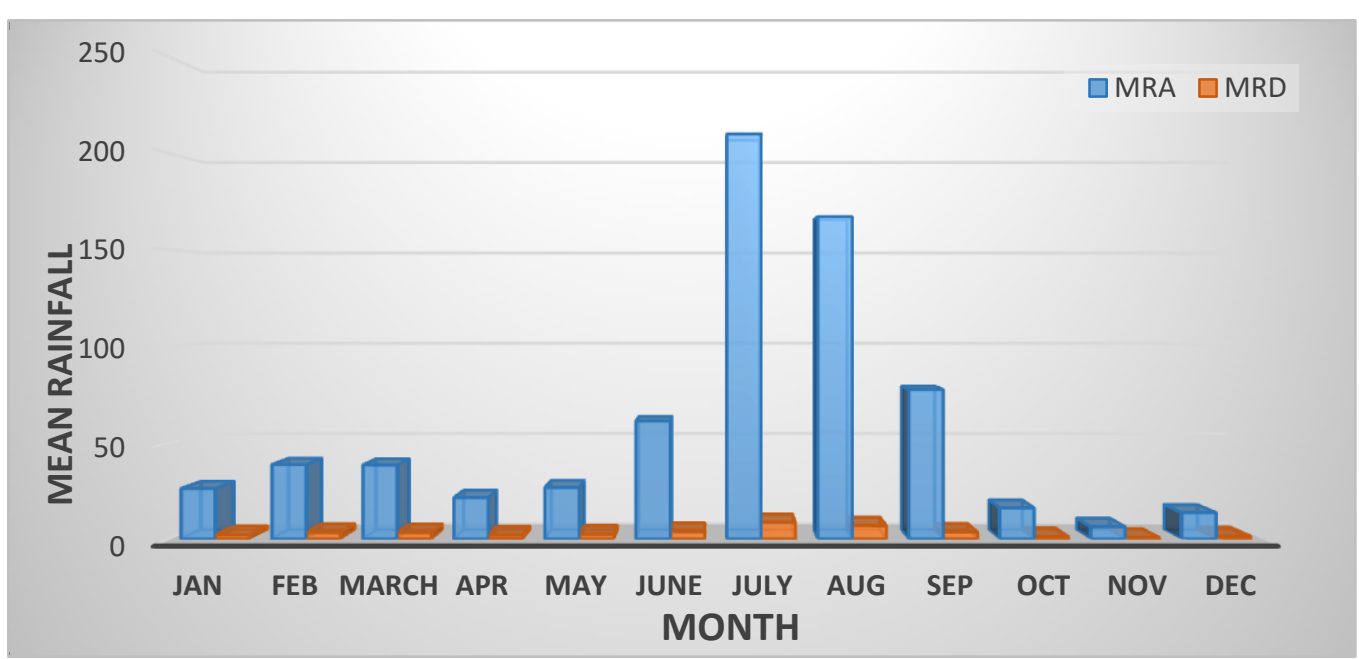

Figure 3: Show the mean rainfall amount (MRA) and mean rainfall day (MRD) in Amritsar

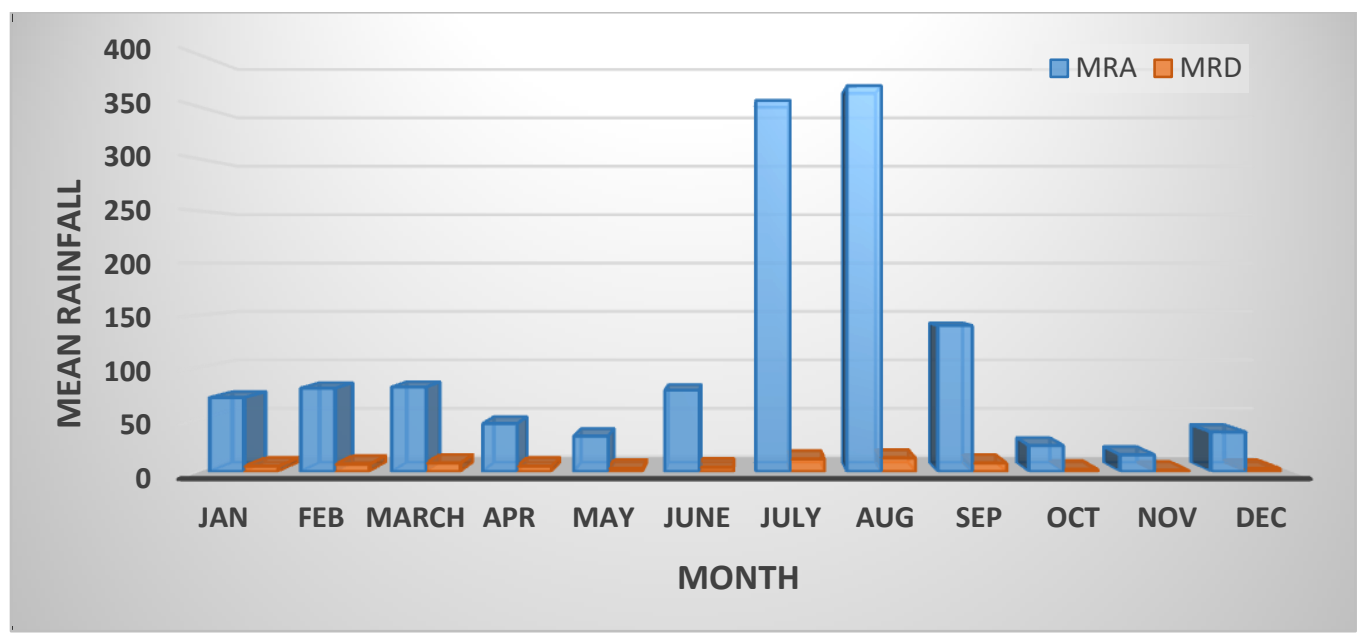

Figure 4: Show the mean rainfall amount (MRA) and mean rainfall day (MRD) in Tarn Taran

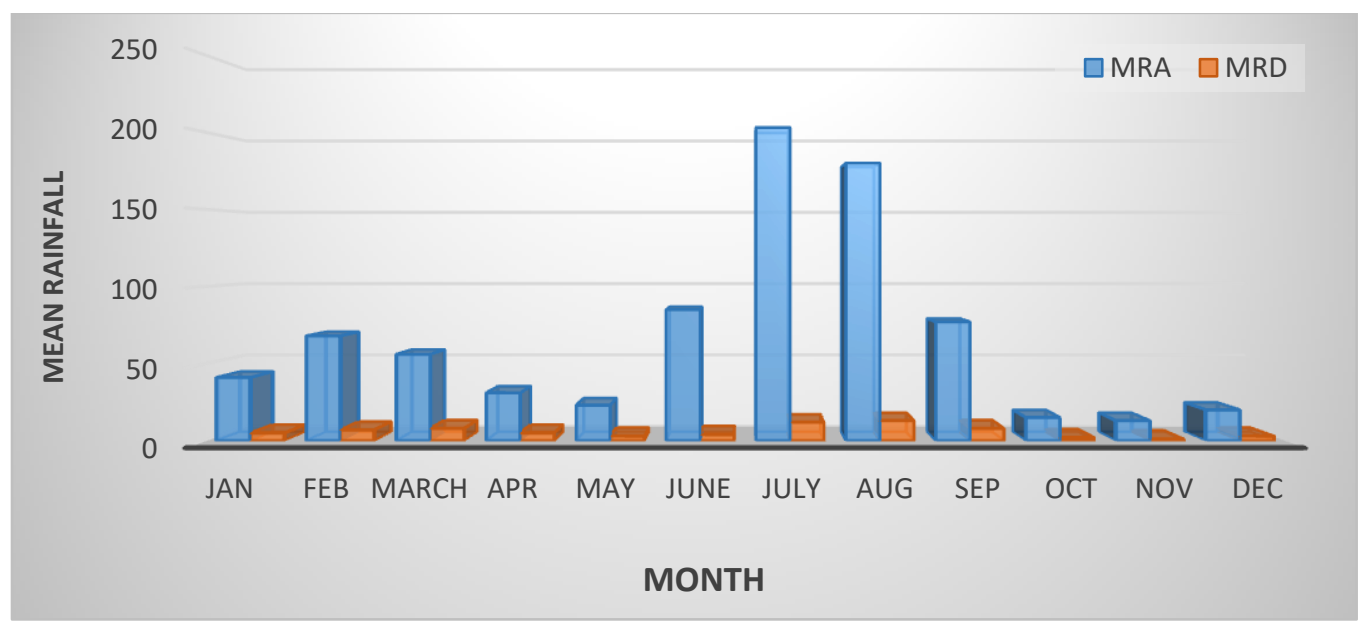

Figure 5: Show the mean rainfall amount (MRA) and mean rainfall day (MRD) in Pathankot

Table 5: Rainfall Intensity (I), Rainfall Energy (E) and Rainfall Erosivity Factor (R) for Tarn Taran

\begin{tabular}{|c|c|c|c|c|c|c|c|}
\hline $\begin{array}{l}\text { MONT } \\
\text { H }\end{array}$ & $\begin{array}{l}\text { I30 } \\
\text { (cm/hr.) }\end{array}$ & $\begin{array}{l}\mathrm{I} 45 \\
(\mathrm{Cm} / \mathrm{hr} .\end{array}$ & $\begin{array}{l}\mathbf{I} 60 \\
(\mathrm{Cm} / \mathrm{hr} .\end{array}$ & $\begin{array}{l}\text { E } \\
\text { (Mjmmha- } \\
\text { 1) }\end{array}$ & $\begin{array}{l}\text { EI30 } \\
\text { (Mjmmha-1hr- } \\
\text { 1) }\end{array}$ & $\begin{array}{l}\text { EI45 } \\
\text { (Mjmmha-1hr- } \\
\text { 1) }\end{array}$ & $\begin{array}{l}\text { EI60 } \\
\text { (Mjmmha-1hr- } \\
\text { 1) }\end{array}$ \\
\hline
\end{tabular}


https://doi.org/10.18510/ijsrtm.2021.932

\begin{tabular}{llllllll}
\hline JAN & 1.23 & 1.11 & 0.99 & 218.1217 & 268.2897 & 242.1151 & 215.9405 \\
\hline FEB & 1.31 & 1.13 & 1.01 & 220.5026 & 288.8584 & 249.1679 & 222.7076 \\
\hline MAR & 1.39 & 1.12 & 0.97 & 222.7423 & 309.6118 & 249.4714 & 216.06 \\
\hline APR & 1.51 & 1.16 & 0.98 & 225.871 & 341.0652 & 262.0104 & 221.3536 \\
\hline MAY & 1.67 & 1.09 & 1.02 & 229.6763 & 383.5595 & 250.3472 & 234.2699 \\
\hline JUNE & 1.75 & 1.19 & 0.99 & 231.4443 & 405.0275 & 275.4187 & 229.1299 \\
\hline JULY & 1.92 & 1.83 & 1.08 & 234.9472 & 451.0986 & 429.9534 & 253.743 \\
\hline AUG & 1.77 & 1.53 & 0.96 & 231.8737 & 410.4164 & 354.7667 & 222.5987 \\
\hline SEP & 1.43 & 1.29 & 1.01 & 223.8142 & 320.0544 & 288.7204 & 226.0524 \\
\hline OCT & 1.31 & 1.15 & 0.94 & 220.5026 & 288.8584 & 253.578 & 207.2724 \\
\hline NOV & 1.29 & 1.17 & 0.95 & 219.9213 & 283.6985 & 257.3079 & 208.9252 \\
\hline DEC & 1.21 & 1.08 & 0.93 & 217.5023 & 263.1778 & 234.9025 & 202.2772 \\
\hline & & & & & $\Sigma=4013.716$ & $\Sigma=3347.76$ & $\mathbf{\Sigma}=2660.33$ \\
\hline
\end{tabular}

Table 6: Rainfall Intensity (I), Rainfall Energy (E) and Rainfall Erosivity Factor (R) for Pathankot

\begin{tabular}{|c|c|c|c|c|c|c|c|}
\hline $\begin{array}{l}\text { MON } \\
\text { TH }\end{array}$ & $\begin{array}{l}\mathbf{I 3 0} \\
(\mathrm{cm} / \mathrm{hr} .)\end{array}$ & $\begin{array}{l}\text { I45 } \\
(\mathrm{cm} / \mathrm{hr} .)\end{array}$ & $\begin{array}{l}\text { I60 } \\
(\mathrm{cm} / \mathrm{hr} .)\end{array}$ & $\begin{array}{l}\text { E } \\
\text { (Mjmmha } \\
-1)\end{array}$ & $\begin{array}{l}\text { EI30 (Mjmmha- } \\
\text { 1hr-1) }\end{array}$ & $\begin{array}{l}\text { EI45 (Mjmmha- } \\
\text { 1hr-1) }\end{array}$ & $\begin{array}{l}\text { EI60 } \\
\text { (Mjmmha- } \\
\text { 1hr-1) }\end{array}$ \\
\hline JAN & 1.21 & 1.09 & 0.97 & 217.5023 & 263.1778 & 237.0775 & 210.9773 \\
\hline FEB & 1.23 & 1.11 & 1.01 & 218.1217 & 268.2897 & 242.1151 & 220.303 \\
\hline MAR & 1.29 & 1.12 & 0.91 & 219.9213 & 283.6985 & 246.3119 & 200.1284 \\
\hline APR & 1.34 & 1.13 & 0.97 & 221.3581 & 296.6199 & 250.1347 & 214.7174 \\
\hline MAY & 1.41 & 1.15 & 0.98 & 223.2821 & 314.8277 & 256.7744 & 218.8164 \\
\hline JUNE & 2.11 & 1.21 & 0.99 & 238.5126 & 503.2615 & 288.6002 & 236.1274 \\
\hline JULY & 2.61 & 1.81 & 1.09 & 246.5477 & 643.4896 & 446.2514 & 268.737 \\
\hline AUG & 2.23 & 1.51 & 0.96 & 240.6025 & 536.5436 & 363.3098 & 230.9784 \\
\hline SEP & 1.53 & 1.23 & 1.01 & 226.3682 & 346.3433 & 278.4328 & 228.6318 \\
\hline OCT & 1.32 & 1.09 & 0.93 & 220.7899 & 291.4427 & 240.661 & 205.3346 \\
\hline $\mathrm{NOV}$ & 1.29 & 1.07 & 0.96 & 219.9213 & 283.6985 & 235.3158 & 211.1245 \\
\hline \multirow[t]{2}{*}{$\overline{\mathrm{DEC}}$} & 1.24 & 1.08 & 0.94 & 218.4277 & 270.8503 & 235.9019 & 205.322 \\
\hline & & & & & $\Sigma=4302.243$ & $\Sigma=3320.887$ & $\Sigma=2651.198$ \\
\hline
\end{tabular}

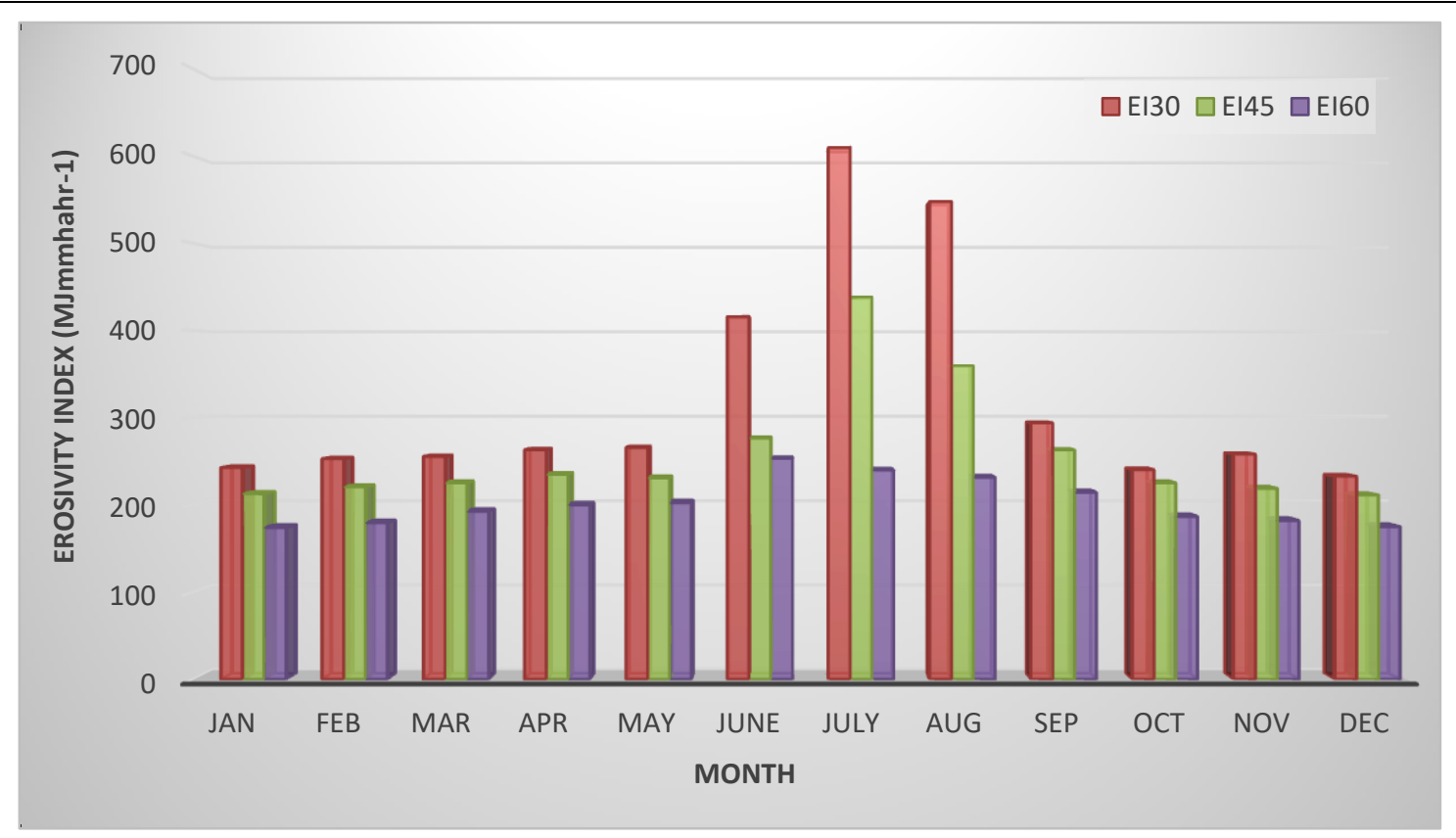

Figure 5: Show the Rainfall Intensity and Rainfall Erosivity Factor (R) for Amritsar 


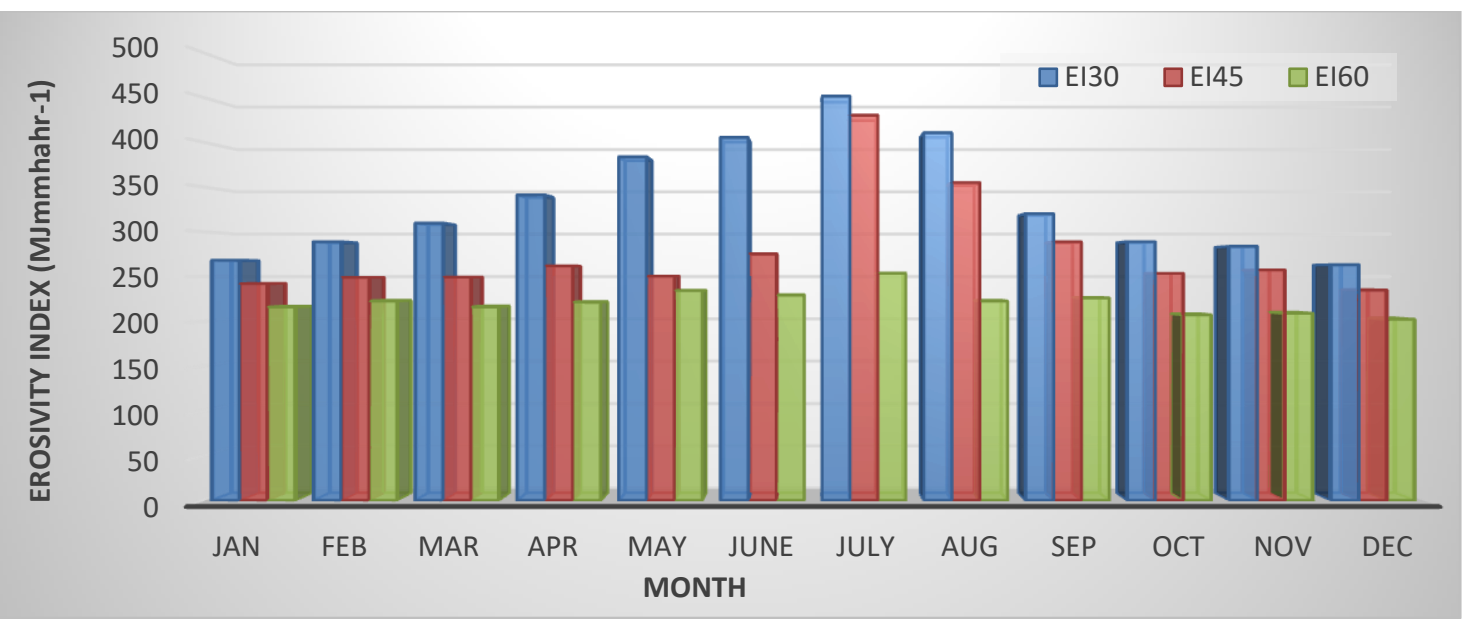

Figure 6: Show the Rainfall Intensity and Rainfall Erosivity Factor (R) for Tarn Taran

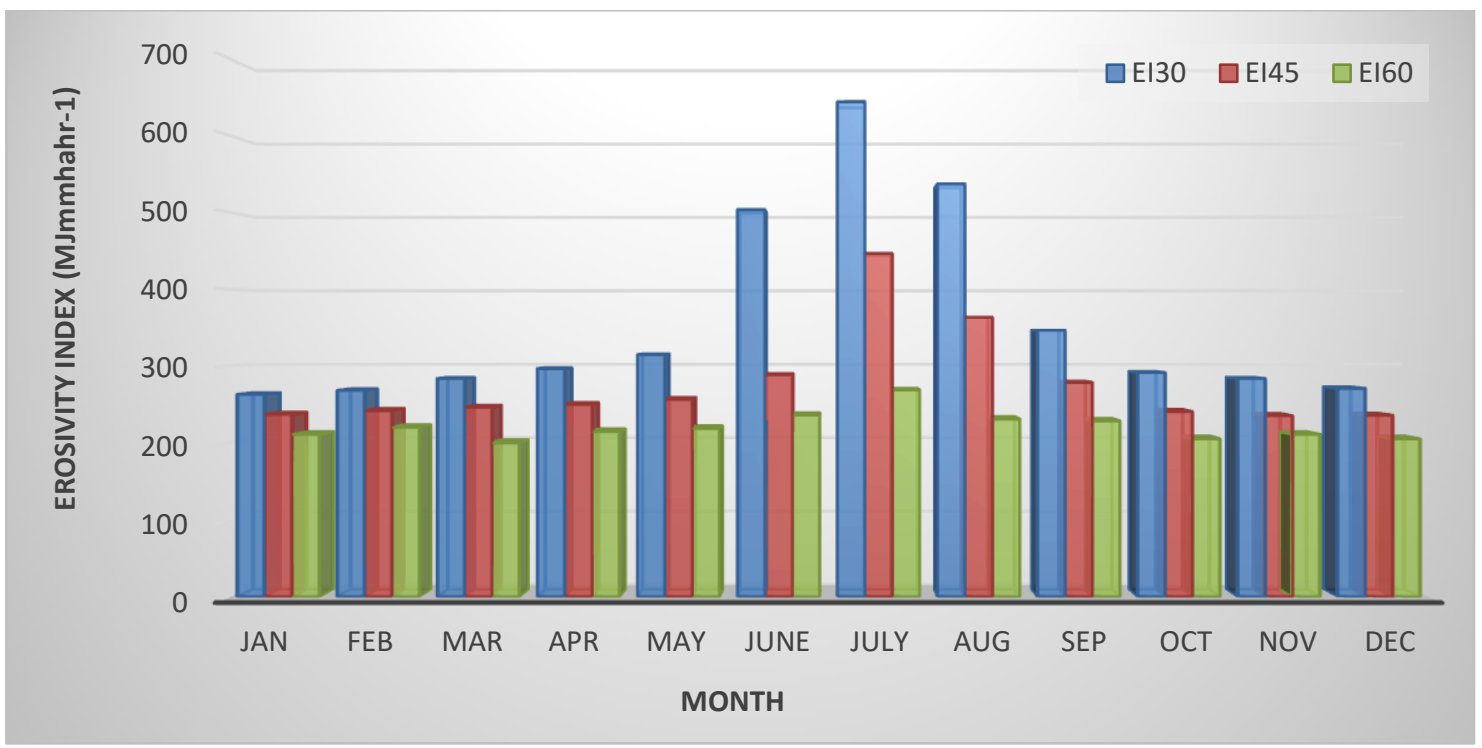

Figure 7: Show the Rainfall Intensity and Rainfall Erosivity Factor (R) for Pathankot

Table 7: Mean Rainfall Erosivity Factor (R) for all the Locations

\begin{tabular}{lll}
\hline Location of Majha region & $\begin{array}{l}\text { Rainfall erosivity Factor (R) } \\
\text { (MJ mmha-1hr-1) }\end{array}$ & Erosivity class \\
\hline Amritsar & 3878.49 & medium erosivity \\
\hline Tarn taran & 4013.71 & medium erosivity \\
\hline Pathankot & 4302.24 & medium erosivity \\
\hline
\end{tabular}

Table 8: Classification of Rainfall Erosivity

\begin{tabular}{ll}
\hline EROSIVITY $\left(\mathbf{M J} \mathbf{~ m m ~ h} \boldsymbol{a}^{\mathbf{- 1}} \mathbf{h} \boldsymbol{-}^{\mathbf{- 1}}\right)$ & EROSIVITY CLASS \\
\hline $\mathrm{R} \leq 2452$ & Low erosivity \\
\hline $2452<\mathrm{R} \leq 4905$ & medium erosivity \\
\hline $4905<\mathrm{R} \leq 7357$ & medium-strong erosivity \\
\hline $7357<\mathrm{R} \leq 9810$ & strong erosivity \\
\hline$<9810$ & very strong erosivity \\
\hline
\end{tabular}

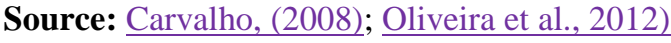

\section{DISCUSSIONS}

From the values displayed in Tables 3.1-3.10, it was observed that as rainfall duration increased, the ratio of rainfall amount to duration (rainfall intensity) decreased accordingly. Likewise, the rainfall erosivity factor (R) at different rainfall intensities also reduced with an increase in rainfall duration. This relationship is dependent on the fact that as rainfall duration increases, the soil undergoes saturation, and pore spaces are filled, thus exceeding infiltration capacity 
at this point, the soil particles no longer undergo detachment or splash but movement so therefore as rainfall duration increases, rainfall intensity keeps decreasing on consistent distribution (Ojha and Michael, 2003).

According to Salako (2010) and Salako (2006), rainfall erosivity factor (R) decreased with an increase in rainfall duration, and it further stated that rainfall erosivity $(\mathrm{R})$ at 15 minutes rainfall intensity gives a better and more precise range of values for erosion prediction and management when compared to higher intensities. For the Majha region, the locations of the rainfall erosivity factor $(\mathrm{R})$ for each of the months varied between643.48 $-232.7762 \mathrm{MJmmha}-1 \mathrm{hr}-1$, the highest rainfall erosivity values were observed in July (rainy season), and the lowest rainfall erosivity values were observed in December (winter season).

The annual rainfall erosivity $(\mathrm{R})$ for the Majha region the all the locations were found to be between 3878.49 (MJmmha1hr-1), 4013.71 (MJmmha-1hr-1), 4302.24 (MJmmha-1hr-1). It was observed that the location having the highest rainfall erosivity factor was Pathankot, and the least rainfall erosivity factor was observed in Amritsar. According to Carvalho (2008) and Oliveira et al. (2012), which states the various degrees or levels of different rainfall erosivity values, the study area fell within the range of medium rainfall erosivity with a value range of 3878.49 (MJmmha-1hr-1), 4013.71 (MJmmha-1hr-1), 4302.24 (MJmmha-1hr-1). At the same time, Balogun et al. (2012) concur that the area is considered a medium erosivity region.

\section{CONCLUSION}

Rainfall erosivity factor $(\mathrm{R})$ for Majha region on each of the locations are as follows, EI = 3878.49 (MJmmha-1hr-1), EI = 4013.71 (MJmmha-1hr-1), EI = 4302.24 (MJmmha-1hr-1) for Majha region of Amritsar, tarn taran and Pathankot respectively. The results statistical analysis and therefore the mean (X), variance (SD), and coefficient of variation were respectively district Amritsar is 58.61, 64.63 and 1.10, Tarn Taran is 67.67, 62.91 and 0.9297 and Pathankot is 111.25, 122.25, and 1.098. The study area falls within the range of medium to high rainfall erosivity with a value range of3878.49 (MJmmha-1hr-1), 4013.71 (MJmmha-1hr-1), 4302.24 (MJmmha-1hr-1). Also, the study area can be classified as an area with medium erosivity, predominantly because of the region in which the study area lies, i.e. subtropical climate zone.

\section{ACKNOWLEDGEMENT}

The scientists of this paper might want to offer their significant thanks to the information/records branch of the Sri Guru Ram Dass Jee International Airport (regional Meteorological centre) Amritsar, Punjab, for giving the precipitation records needed for this investigation.

\section{REFERENCE}

1. Agricultural Research Services (ARS), (1961). USDA. A universal equation for predicting rainfall erosion losses. ARS, 22-26.

2. Angelo- Martinez, M. and Begueria, S. (2009). Estimating Rainfall erosivity from daily precipitation records: A comparison among methods using data from Ebro Basin (NE Spain), Elsevier Journal of Hydrology, 379(2009) 111-121. https://doi.org/10.1016/j.jhydrol.2009.09.051

3. Balogun. I., Adegun, O., Adeaga, O. (2012). An assessment of rainfall erosivity in parts of eastern Nigeria: a case study of Owerri and Enugu. Hydrology for Disaster Management. Special Publication of the Nigerian Association of Hydrological Sciences.

4. Carvalho, N.O. (2008). Hidrossedimentologia Prática, 2a ed. Interciência, Rio da Janeiro, Brazil. 599 pp.

5. Dai, Q., Zhu, J., Zhang, S., Zhu, S., Han, D., and Lv, G (2020). Estimation of rainfall erosivity based on WRFderived raindrop size distributions, Hydro. Earth Syst. Sci., 24, 5407-5422, https://doi.org/10.5194/hess-245407-2020, https://doi.org/10.5194/hess-24-5407-2020

6. Michael, A.M. and Ojha, T.P. (2003). Principles of Agricultural Engineering, Volume II, Jain Publishers, New Delhi, India 3-436 pp.

7. Nearing, M.A., Yin, S., Borelli, P., Polyakov, V.O. (2017). Rainfall erosivity: An historical review. Catena, 157, 357-362. https://doi.org/10.1016/j.catena.2017.06.004

8. Oliveira, P.T.S., Wendland, E. and Nearing, M.A. (2012). Rainfall Erosivity in Brazil: A review. CATENA, 100, 139-147. https://doi.org/10.1016/j.catena.2012.08.006

9. Okorafor, O.O., Akinbile, C. O., Adeyemo, A. J. and Egwuonwu, C. C. (2017). Determination of Rainfall Erosivity Index (R) for Imo State. American Journal of Engineering Research, 6(2), 13-16.

10. Powlson, D. S., Gregory, P. J., Whalley, W. R., Quinton, J. N., Hopkins, D. W., Whitmore, A. P., Hirsch, P. R., Goulding, K. W. T., (2011). Soil Management in Relation to Sustainable Agriculture \& Ecosystem services. Food Policy Guidelines, 36(2), 72-87.https://doi.org/10.1016/j.foodpol.2010.11.025

11. Renard, K. G., Foster, G. R., Weenies, G. A, McCool, D. K. and Yoder, D.C. (1997). Predicting soil erosion by water: A guide to conservation planning with the revised universal soil loss equation (RUSLE)USDA, Agriculture Handbook No.703, Washington DC 126-143.

12. Salako, F.K. (2010). Development of Isoerodent maps for Nigeria from daily rainfall amount. Geoderma, 156, 372-378. https://doi.org/10.1016/j.geoderma.2010.03.006 
13. Satapathy, K.K., Jena, S.K., and Daschaudhuri D. (2000). Erosion Index Analysis of Umiam, Meghalaya. Indian J. Soil Cons. 28(3), 193-197.

14. Sanchez-Moreno, J.F, Mannaerts C.M and Jetten, V. (2013). Rainfall Erosivity Mapping for Santiago, Cape Verde. Geoderma 217, 74-82. https://doi.org/10.1016/j.geoderma.2013.10.026

15. Talchabhadel, R., Nakagawa, H., Kawaike, K. et al. (2020). Evaluating the rainfall erosivity (R-factor) from daily rainfall data: an application for assessing climate change impact on soil loss in Westrapti River basin, Nepal Model. Earth Syst. Environ., 6, 1741-1762 https://doi.org/10.1007/s40808-020-00787-w, https://doi.org/10.1007/s40808-020-00787-w

16. Yin, S., Xie, Y., Nearing, M.A and C. Wang (2007). Estimation of Rainfall Erosivity using 5-60-minute fixed interval rainfall data from China. Catena, 70, 300-312. https://doi.org/10.1016/j.catena.2006.10.011

17. Bullock, P.R., Ede Jong and Kiss, J.J. (1990). An assessment of rainfall erosion potential in Southern Saskatchewan from daily rainfall records. Can. Agaric, Eng., 32, 17-24.

18. Elangovan, A. B. and Seetharaman, R. (2011). Estimating Rainfall Erosivity of the Revised Universal Soil Loss Equation from daily rainfall depth in Krishnagiri Watershed region of Tamil Nadu, India. International Conference on Environmental and Computer Science vol.19.

19. Fayas, C. S. (2019). Soil Loss Estimation Using RUSLE Model to Prioritize Erosion Control in KELANI River Basin in Sri Lanka. International Soil and Water Conservation Research, 7(2), 130-137. https://doi.org/10.10 16/i.iswcr.2019.01.003

20. Favis-Mortlock, A., Boardman, J., \& MacMillan, V. (2001). The Limits of Erosion Modeling: Why We Should Proceed with Care. In R. S. Harmon, \& W. W. Doe III, Landscape Erosion and Evolution Modeling (S. 477516). Boston: Springer. https://doi.org/10.1007/978-1-4615-0575-4_16

21. Gelagay, H.S. and Minale, A.S. (2016). Soil Loss estimation using GIS and remote sensing techniques: A cast of Koga watershed, Northwestern Ethiopia. International Soil and Water Conservation, 4, 126-136. https://doi.org/10.1016/j.iswcr.2016.01.002

22. Jain, S. and Narain, S. (1995). Development of Erosivity Index on Daily Rainfall Basis. B.Tech. Thesis in Agricultural Engineering. G. B. Pant University of Agriculture and Technology, Pantnagar.

23. Lo, A., El-Swaify, S., \& Dangler, E. \&. (2016). Effectiveness of EI 30 as an Erosivity Index in Hawaii. Fao, Available online: http://agris.fao.org/agr is search/search.do? Record ID =US8639059

24. Marco da Silva, A. (2004). Rainfall erosivity map for Brazil. Catena, 57, 251 - 259. https://doi.org/10. 1016/j.catena.2003.11.006

25. Okorafor, O.O, Akinbile, C.O and Adeyemo, A.J. (2018). Determination of Soils Erodibility Factor (K) for Selected Sites in Imo State, Nigeria. Resources and Environment, 8(1), 6-13.

26. Soo Huey Teh, (2011). Soil Erosion modelling using RUSLE and GIS on Cameron Highlands, Malaysia for hydropower Development. A master's thesis was published by the school for renewable energy science, the University of Iceland and Akureyri.

27. Selemo, A.O, Ananaba, S.E, Nwagbara, J.O, Egejuru, V.E and V. Nwugha, (2012). Geostatistical Analysis of Rainfall Temperature and evaporation Data of Owerri for Ten years. Journal of Earth and Environmental Sciences, 2, 195-205. https://doi.org/10.4236/acs.2012.22020

28. Teh, H.S (2011). Soil Erosion Modeling using GIS and RUSLE for Cameron Highlands, Malaysia for Hydropower Development, School of Renewable Energy Studies, University of Iceland 29-45 pp.

29. Udokporo, E, Anikwe, M.A.N and K.E. Chukwu (2015). Assessment and mapping of the Vulnerability of soils in Imo State Nigeria to erosion hazard using GIS. International Journal of Environmental Monitoring and Analysis, 3(5), 245-259. https://doi.org/10.11648/j.ijema.20150305.12

30. Ufot, U.O., Iren, O.B., and C.U. Chikere-Njoku (2016). Effects of Land use on soil physical and chemical properties in Akokwa area of Imo State, Nigeria. International Journal of Life, Science and Scientific Research, 2(3),1-6. https://doi.org/10.21276/ijlssr.2016.2.3.14

31. Wang, B., Zheng, F., Romkas, M. J. M and F. Darboux, (2013). Soil Erodibility for Water Erosion; A Perspective and Chinese Experiences, Journal of Geomorphology, 187, 1-10. https://doi.org/10.1016/j.geo morph.2013.01.018

32. Webb, N.P., Marshall, N.A., Stringer, L.C., Reed, M.S., Chappell, A., Herrick, J.E. (2017). Land degradation and climate change: Building climate resilience in agriculture. Front. Ecol. Environ., 15, 450-459. https://doi.org/10.1002/fee.1530 